\title{
Effects of Salt Stress on Chlorophyll Fluorescence and the Antioxidant System in Ginkgo biloba L. Seedlings
}

\author{
Haiyan Zhao \\ College of Biological Sciences and Biotechnology, Beijing Forestry \\ University, Beijing, 100083, People's Republic of China \\ Haiying Liang \\ Department of Genetics and Biochemistry, 154 Poole Agricultural Center, \\ Clemson University, Clemson, SC 29634
}

Yibing Chu and Congcong Sun

College of Biological Sciences and Biotechnology, Beijing Forestry University, Beijing, 100083, People's Republic of China

Ning Wei

College of Forestry, Beijing Forestry University, Beijing, 100083, People's Republic of China

\section{Mengnan Yang and Caixia Zheng \\ College of Biological Sciences and Biotechnology, Beijing Forestry University, Beijing, 100083, People's Republic of China}

Additional index words. antioxidant enzymes, chlorophyll content, Ginkgo biloba, photosystem II, salt tolerance

\begin{abstract}
Ginkgo biloba L. (ginkgo) is generally regarded as a tolerant species to environmental stresses. However, its tolerance mechanisms are not well understood, particularly for salt stress. To evaluate the species' physiological responses to salt stress, 3-year-old ginkgo seedlings were exposed to a range of salinity levels $(0 \%$ to $1.0 \% \mathrm{NaCl})$. A significant reduction in maximum $\left(F_{\mathrm{v}} / F_{\mathrm{m}}\right)$ and actual $\left(\Phi_{\mathrm{PSII}}\right)$ quantum yields of photosystem II (PSII) photochemistry and the nonphotochemical quenching $\left(q_{N}\right)$ coefficient only occurred in late treatment stages at the salinity levels of $0.6 \%$ to $1.0 \%$. As salt concentration increased, the response time and chlorophyll (Chl) fluorescence indices decreased. Overall, the activities of superoxide dismutase (SOD) and peroxidase (POD); contents of catalase (CAT), reduced glutathione (GSH), and flavonoids; and scavenging rate of free radicals enhanced under salinity stress. These data indicate that ginkgo seedlings are tolerant to low salt stress, and enzymatic and nonenzymatic antioxidant systems seem to work synergistically to reduce lipid oxidation under $\mathrm{NaCl}$ stress because malondialdehyde (MDA) content did not increase. Correlation and principal component analyses determined that water potential, Chl fluorescence parameters, activities of POD and SOD, contents of CAT and flavonoids, and hydroxyl $(\bullet \mathrm{OH})$ and diphenyl picrylhydrazyl (DPPH) free radical scavenging capability were sensitive to salt stress. These parameters can be used for in vitro or rapid and nondestructive monitoring of the responses of ginkgo seedlings to salinity stress. It is of significance to understand the tolerance mechanisms of ginkgo to salt stress, reduce the harm of $\mathrm{NaCl}$ and other snow-melting agents to ginkgo as shade trees, and develop new salt-tolerant varieties.
\end{abstract}

Ginkgo biloba L. (ginkgo), primarily endogenous to China (Gong et al., 2008; Tredici 2008), is the only extant species in the Ginkgoaceae family and occupies a unique position in the history of plant evolution as the oldest relic of gymnosperms. The species

\footnotetext{
Received for publication 29 July 2019. Accepted for publication 30 Aug. 2019.

This work was supported by the National Natural Science Foundation Program of China (nos. 30371144, 30671655, and 31170563).

C.Z. is the corresponding author. E-mail: zhengcx@ bjfu.edu.cn.
}

is priced for its medicinal (DeFeudis et al., 2003; Rainer et al., 2018), ecological, and ornamental values. Ginkgo nut is also a traditional source of food in China and Japan (van Beek and Montoro, 2009). Ginkgo is widely cultivated as an important ornamental and street tree in many urban areas throughout much of the United States, China, Japan, and other countries because of its features, such as a straight trunk; unique two-lobe, fanshape leaves that turn vivid yellow in fall (Handa et al., 1997; Sæbø et al., 2005); and high resistance to pests, diseases (Guan et al., 2016), and general tolerance of inhospitable growing conditions (Dmuchowski et al., 2019; Swoczyna et al., 2015). In China, this species has become a national symbol of its botanical heritage.

Given the intensification of soil salinization resulting from climate and environmental changes, and the extensive use of snowmelting agents in urban streets, studying the physiological mechanism of salt tolerance of ginkgo and identifying salt-tolerant varieties are urgently needed. High salt levels can lead to a series of changes in morphology, physiology, biochemistry, and molecular biology of cells and tissues in many plant species (Gupta and Huang, 2014; Munns and Tester, 2008). Consequently, salt stress can hinder growth and even result in mortality (Bidalia et al., 2017). Salt inhibits the differentiation of plant tissues and organs, reduces the incidence of leaf primordia, accelerates plant development, and causes presenility or death (Grieve et al., 1994). Salt stress increases chloroplast enzyme activity and acceleration of Chl decomposition (Megdiche et al., 2008), and decreases photosynthesis (Stępień and Kłobus, 2006). Furthermore, activities of phosphoenolpyruvate carboxylase and ribulose bisphosphate carboxylase are reduced (Seemann and Critchley, 1985), thereby adversely affecting carbon assimilation (Matoh and Murata, 1990). Another significant consequence of salinity stress in plants is the excessive generation of reactive oxygen species (ROS), such as $\mathrm{O}_{2}{ }^{\bullet-}, \mathrm{H}_{2} \mathrm{O}_{2}, \bullet \mathrm{OH}$, and ${ }^{1} \mathrm{O}_{2}$ (Apel and Hirt, 2004). Salt damage can seriously disrupt normal metabolism through oxidative damage to proteins, lipid, DNA, and, ultimately, cellular structures (Apel and Hirt, 2004). The original ion balance of $\mathrm{K}^{+} / \mathrm{Na}^{+}$in plant cells is broken when $\mathrm{Na}^{+}$content in the soil is extremely high, leading to osmotic stress and ionic toxicity accompanied by reduced $\mathrm{K}^{+}$and $\mathrm{Ca}^{2+}$ (Maimaiti et al., 2014; Silva et al., 2010).

Currently, three salt tolerance mechanisms have been revealed: a salt-secreted mechanism that removes salinity through saline glands in leaves and stems, a saltrejected mechanism that prevents salt ions from entering the plants and redistributes salt ions to safety sites, and a salt-diluted mechanism that transports salt ions to plant vacuoles (Breckle, 1995), thereby reducing the toxicity of salt ions to important organelles and enzymes in cytoplasm (Greenway and Munns, 1980). Salt tolerance is associated with osmotic and ionic stress tolerance, reactive oxygen scavenging, and changes in metabolic pathways and tissue morphology. At the molecular level, salt stress is related to signal transduction of mitogen-activated protein kinase (Apel and Hirt, 2004), salt hypersensitive signal transduction, abscisic acid signal transduction pathway ( $\mathrm{Zhu}, 2002$ ), calcineurin signal transduction (Pardo et al., 1998), and signal transduction pathways involving other protein kinases.

Compared with studies of other species, studies of salt response and tolerance mechanisms on ginkgo are limited, although ginkgo is generally considered to have a 
strong overall adaptability and recovery capability. According to its genome sequencing results, ginkgo has undergone genome-wide replication and has a large number of long terminal repeat insertion events. Gene families that provide various defense mechanisms are widely amplified as a result of its longterm evolution. For instance, a dual defense mechanism against insect attacks has been found (Guan et al., 2016). Currently available stress studies in ginkgo focus mainly on drought, waterlogging, heavy metal contamination, suboptimal light conditions, and ozone (Chen et al., 2014; Liang and Sun, 2002). Chen et al. (2014) reported that cell growth and flavonoid accumulation were stimulated at low salt doses $(5-50 \mathrm{~mm})$ in suspension-cultured ginkgo cells. As salt concentration increased, the following parameters also increased: dry/fresh weight of suspended cells, Chl $a$, Chl $b$, Chl $(a+b)$, $F_{\mathrm{v}} / F_{\mathrm{m}}, \mathrm{q}_{\mathrm{N}}, \Phi_{\mathrm{PSII}}$, and the photochemical quenching coefficient $\left(\mathrm{q}_{\mathrm{P}}\right)$. However, at greater salinity levels $(150-175 \mathrm{~mm})$, the cell structure was destroyed, antioxidant enzyme activity decreased, and flavonoids were not induced to cope with greater accumulation levels of $\mathrm{H}_{2} \mathrm{O}_{2}$ (Chen et al., 2014).

Our previous study showed that although a 64 -d treatment with $0.2 \% \mathrm{NaCl}$ decreased water potential in 3-year-old plants, height growth and ground diameter were not adversely affected until the $\mathrm{NaCl}$ concentration reached $0.6 \%$ and $0.8 \%$, respectively (Zhao et al., 2018). Observation with scanning electron microscopy (SEM) also showed that salt crystal clusters accumulated in stem parenchymal cells but not in the roots and leaves (Zhao et al., 2018). In another previous study, we found that soluble protein, soluble sugar, and proline were mainly accumulated and used for osmotic adjustment in ginkgo under $\mathrm{NaCl}$ stress, and the synergistic effect of $\Delta^{1}$-pyrroline-5-carboxylate synthetase, ornithine- $\delta$-aminotransferase, and proline dehydrogenase promoted the accumulation of proline (Sun et al., 2017). In the current study, we investigated the physiological responses of ginkgo seedlings to different doses of $\mathrm{NaCl}$ and evaluated their salt tolerance by tracking changes in Chl fluorescence and antioxidant and nonenzyme systems. Our goal was to understand the response mechanisms of ginkgo to salt stress. Because the species is currently facing the challenge of snow-melting agents and soil salinization, the results of our study will provide a theoretical basis for developing new salt-tolerant varieties and guidelines for the use of ice-melting chemicals. It may also help expand ginkgo planting areas in saline areas.

\section{Materials and Methods}

Plant materials and growth conditions. Three-year-old healthy ginkgo seedlings (diameter, $1.0-1.3 \mathrm{~cm}$; height, $80-100 \mathrm{~cm}$ ) were collected from a ginkgo nursery in Xuzhou, Jiangsu Province, China. Seedlings were transplanted into $10-\mathrm{L}$ polyethylene pots on 18 Mar. 2015. The potting mix comprised an equal combination of local soil and peat $(\mathrm{v} / \mathrm{v})$. All seedlings were placed in a wellventilated plastic shed at a nursery at Beijing Forestry University (lat. $40^{\circ} 01^{\prime} \mathrm{N}$, long. $116^{\circ} 35^{\prime} \mathrm{E}$ ) for 3 months before the salt stress treatment was applied. The daytime/nighttime temperatures were $29 \pm 4{ }^{\circ} \mathrm{C} / 20 \pm 3{ }^{\circ} \mathrm{C}$, the averaged relative humidity was $65 \%$, and photosynthetically active radiation $(P A R)$ was $500 \mu \mathrm{mol} \cdot \mathrm{m}^{-2} \cdot \mathrm{s}^{-1}$, with an average of $217 \mathrm{~h}$ sunshine per month during the experiment period.

Salt treatment. A total of 30 healthy seedlings of similar height were selected and divided randomly into six groups (five plants per group). $\mathrm{NaCl}$ solutions (500 $\mathrm{mL}$ each) were prepared in concentrations of $0.2 \%$, $0.4 \%, 0.6 \%, 0.8 \%$, or $1.0 \%$ with tap water and were applied to the pots once per week. The control seedlings were treated with an equal volume of tap water $(0 \% \mathrm{NaCl})$. Healthy leaf samples were collected at various time points from similar locations among individual plants, frozen rapidly in liquid nitrogen, and stored at $-80{ }^{\circ} \mathrm{C}$ for measurement of physiological indexes, unless otherwise indicated. No leaves from the $1.0 \%$ treatment group in $64 \mathrm{~d}$ were available for collection as a result of severe wilting and defoliation. At $64 \mathrm{~d}$ of treatment, the soil salt concentrations were calculated as described in Zhao et al. (2018) and were determined to be $0.22 \%, 0.44 \%$, $0.57 \%, 0.84 \%, 0.95 \%$, and $1.11 \%$ for the $0 \%$, $0.2 \%, 0.4 \%, 0.6 \%, 0.8 \%$, and $1.0 \% \mathrm{NaCl}$ treatments, respectively. After $66 \mathrm{~d}$ of treatment, all groups were irrigated with tap water.

Determination of pigmentation content. Leaves (0.2 g, fresh weight) from each treatment time point of $8,15,36$, and $64 \mathrm{~d}$ after salt treatment were ground individually in an ice bath mortar with silica sand, calcium carbonate powder, and $10 \mathrm{~mL}$ ethanol $(96 \%$, $\mathrm{v} / \mathrm{v})$. After filtration, the extracts were transferred into a flask and brought up to a volume of $25 \mathrm{~mL}$ with $96 \%$ ethanol. Chl $a, \mathrm{Chl} b$, and carotenoid (Car) contents were determined according to Arnon (1949) and Lichtenthaler (1987). The absorbance of centrifuged extracts was recorded at 665,649 , and $470 \mathrm{~nm}$ using an ultraviolet-visible light doublebeam spectrophotometer (UV-4802; Unico, Shanghai, China).

Analysis of Chl fluorescence parameters. Chl fluorescence parameters were monitored with a portable $\mathrm{Chl}$ fluorescence device (Junior-PAM; Walz, Germany) at $1000 \mathrm{HR}$ after 1, 2, 3, 8, 22, 29, 36, 44, 50, 57, and $64 \mathrm{~d}$ of $\mathrm{NaCl}$ treatment. After dark adaptation for $30 \mathrm{~min}$, the leaves were initially exposed to a weak modulated measuring beam of radiation $\left(5 \mathrm{~Hz}, 0.1 \mu \mathrm{mol} \cdot \mathrm{m}^{-2} \cdot \mathrm{s}^{-1} P A R\right)$ to determine minimal fluorescence $\left(F_{\mathrm{o}}\right)$. Then, the maximal fluorescence $\left(F_{\mathrm{m}}\right)$ was measured using a saturation pulse $\left(5000 \mu \mathrm{mol} \cdot \mathrm{m}^{-2} \cdot \mathrm{s}^{-1}\right.$ $P A R$; duration, $800 \mathrm{~ms}) ; F_{\mathrm{v}} / F_{\mathrm{m}}$ was calculated as $\left(F_{\mathrm{m}}-F_{\mathrm{o}}\right) / F_{\mathrm{m}}$. After actinic light was switched on for $1 \mathrm{~min}\left(100 \mu \mathrm{mol} \cdot \mathrm{m}^{-2} \cdot \mathrm{s}^{-1}\right.$ $P A R), 10$ saturation pulses were triggered to measure maximal $\mathrm{Chl}$ fluorescence in the light-adapted state $\left(F_{\mathrm{m}}{ }^{\prime}\right)$. $\Phi_{\text {PSII }}$ was calculated as $\left(F_{\mathrm{m}}{ }^{\prime}-F_{\mathrm{s}}\right) / F_{\mathrm{m}}{ }^{\prime}$ according to Genty et al. (1989). $\mathrm{q}_{\mathrm{P}}$ and $\mathrm{q}_{\mathrm{N}}$ were calculated according to Havaux et al. (1991) as follows: $\mathrm{q}_{\mathrm{P}}=\left(F_{\mathrm{m}}{ }^{\prime}-F_{\mathrm{s}} /\left(F_{\mathrm{m}}{ }^{\prime}-F_{\mathrm{o}}\right), \mathrm{q}_{\mathrm{N}}=\left(F_{\mathrm{m}}-F_{\mathrm{m}}{ }^{\prime}\right) /\right.$ $\left(F_{\mathrm{m}}-F_{\mathrm{o}}\right)$.

Measurement of cell damage induced by salt treatment. To estimate cell damage induced by salt treatment, relative electrical conductivity (REC) was measured with a LaMotte Conductivity Meter (LaMotte CON6, USA) to assess cell membrane permeability, according to the method of Sun et al. (2010). Specifically, 10 leaf disks from an individual plant were collected using a 0.6-cm-diameter hole punch; these were placed immediately in a tube with $10 \mathrm{~mL}$ distilled water. The air in the tube was removed with a vacuum pump for $20 \mathrm{~min}$ and the tube was allowed to stand for $40 \mathrm{~min}$ at room temperature before the electrical conductivity $\left(\mathrm{S}_{1}, \mu \mathrm{S} \cdot \mathrm{cm}^{-1}\right)$ of the solution was recorded. The samples were then boiled for $15 \mathrm{~min}$ and the electrical conductivity $\left(\mathrm{S}_{2}\right.$, $\mu \mathrm{S} \cdot \mathrm{cm}^{-1}$ ) was recorded after cooling to room temperature. The REC of the samples was calculated as $\left(\mathrm{S}_{1} / \mathrm{S}_{2}\right) \times 100 \%$.

The MDA level in the leaves was measured using the thiobarbituric acid (TBA) method (Heath and Packer, 1965). Briefly, $0.2 \mathrm{~g}$ fresh leaves from each plant was homogenized with $5.0 \mathrm{~mL} 10 \%$ trichloroacetic acid solution and silica sand, followed by centrifugation at $2000 \mathrm{rpm}$ for $10 \mathrm{~min}$. The supernatant $(2.0 \mathrm{~mL})$ was collected and mixed with $2.0 \mathrm{~mL} 0.6 \%$ TBA. Absorption was recorded at 450, 532, and $600 \mathrm{~nm}$.

Evaluation of the antioxidant system. Leaves ( $0.2 \mathrm{~g}$, fresh weight) without midribs were homogenized in an ice bath mortar with $0.05 \mathrm{~mol} \cdot \mathrm{L}^{-1}$ phosphate-buffered saline (PBS; $\mathrm{pH} 7.0$ ) and placed in a tube with $5 \mathrm{~mL}$ PBS. The homogenates were centrifuged at 10,000 rpm for $15 \mathrm{~min}$ at $4{ }^{\circ} \mathrm{C}$ to obtain supernatants for further analyses. The activities of SOD, CAT, and POD were estimated using nitroblue tetrazolium (Stewart and Bewley, 1980), the guaiacol test (Polle et al., 1994), and the method of Chance and Maehly (Aebi, 1984), respectively. GSH and flavonoid levels were determined using colorimetric methods described previously (Guri, 1983; Jia et al., 1999). DPPH and $\cdot \mathrm{OH}$ radical scavenging activities were assessed according to methods described by Hsu et al. (2008) and Mathew and Abraham (2006), respectively.

Data analyses. At least three technical repeats were performed for each assay, and the data were processed using SPSS version 23.0 (SPSS Inc., Chicago, IL) for statistical and principle component analyses. One-way analysis of variance was performed to identify statistically significant differences among treatments, followed by Duncan's multiple range test at $P<0.05$. Pearson's correlation coefficient was used for correlation analysis. Raw data for water potential and plant growth included in correlation and principle component analyses were acquired from our previous report of ginkgo plants using the same experimental design (Zhao et al., 2018). Charts were made using Origin 8.0 software. 

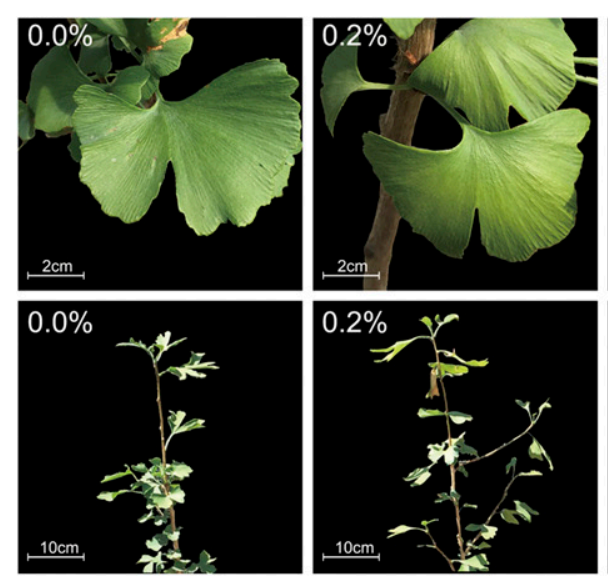
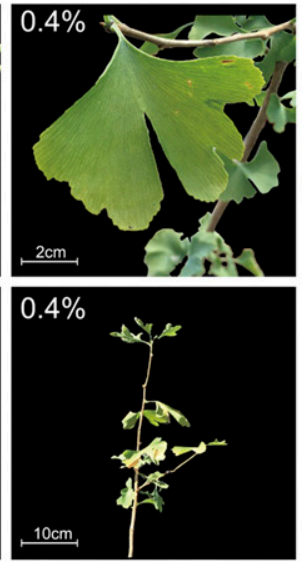
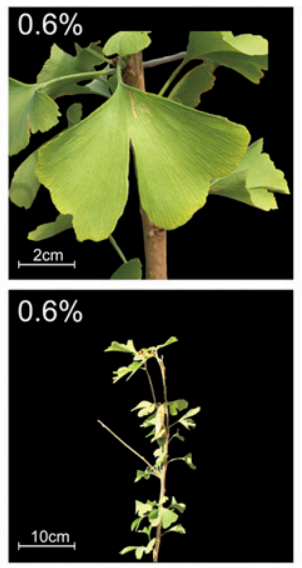
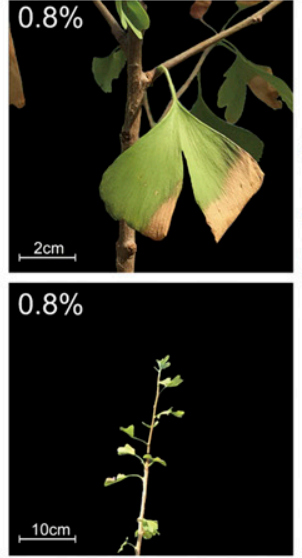
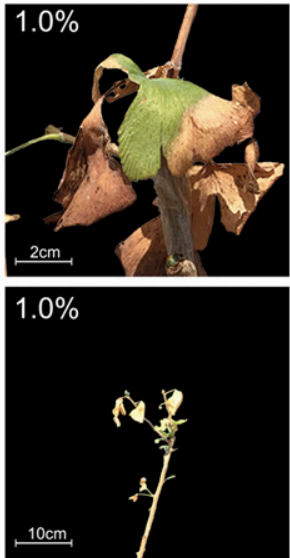

Fig. 1. Leaves and stems of 3 -year-old ginkgo seedlings grown under various $\mathrm{NaCl}$ concentrations $(0 \%, 0.2 \%, 0.4 \%, 0.6 \%, 0.8 \%, 1.0 \%)$ after $64 \mathrm{~d}$.

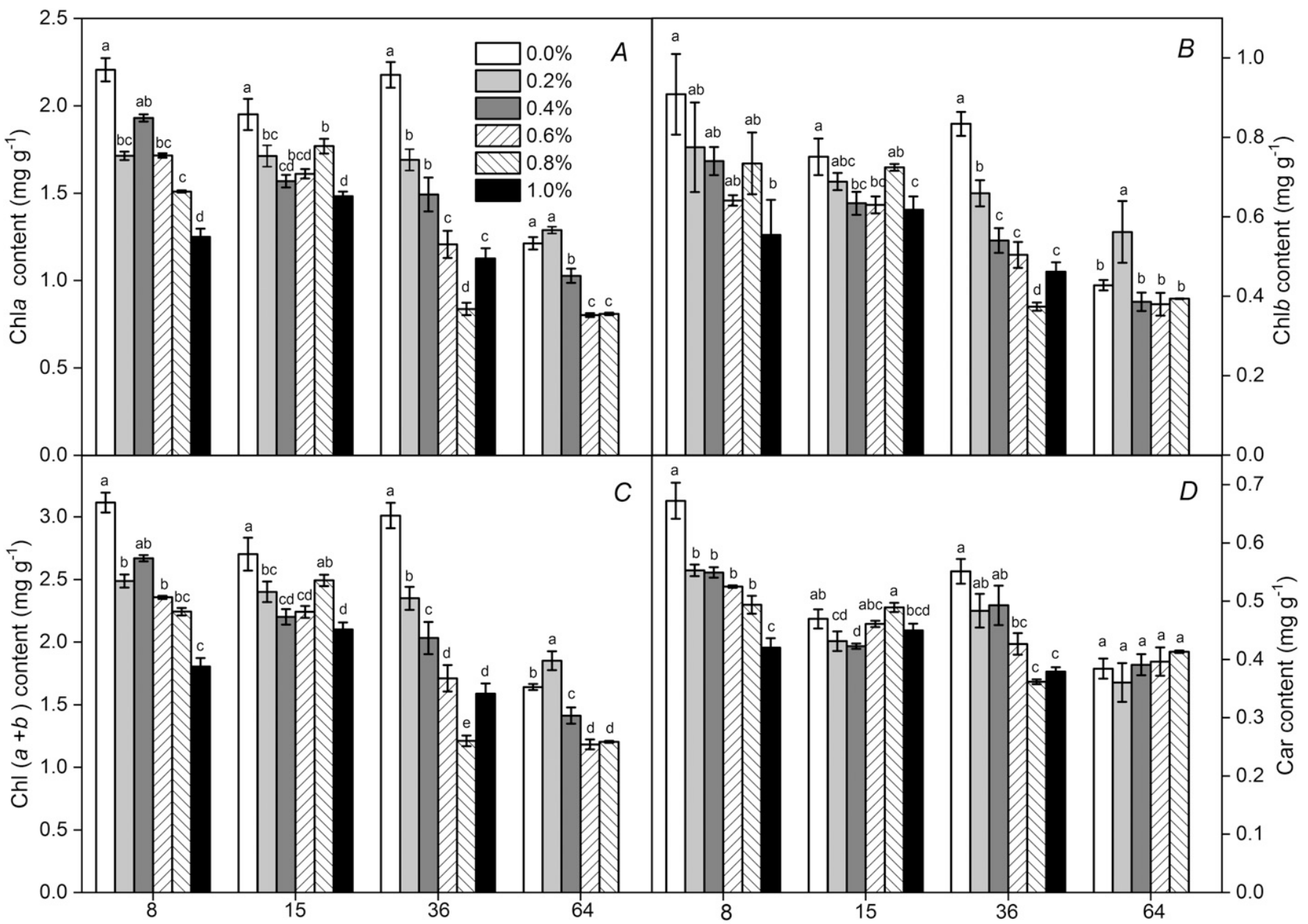

Duration of $\mathrm{NaCl}$ treatment (d)

Fig. 2. (A-D) Effect of $\mathrm{NaCl}$ on the contents of chlorophyll (Chl) and carotenoid (Car) in leaves of 3-year-old ginkgo seedlings treated for 8, 15, 36, and 64 d. Data are mean $\pm \mathrm{SE}, \mathrm{n}=5$. Within the same time point, different letters indicate a significant difference by Duncan's multiple range test $(P<0.05)$.

\section{Results}

Changes in pigment content under salinity stress. As shown in Fig. 1, leaf wilting was observed in the $0.8 \%$ and $1.0 \% \mathrm{NaCl}$ treatment groups $64 \mathrm{~d}$ after treatment. Pigment content largely decreased significantly as
$\mathrm{NaCl}$ concentration and treatment duration increased (Fig. 2). For instance, $1.0 \% \mathrm{NaCl}$ significantly reduced all types of pigments, including Chl $(a+b)$, Chl $a$, Chl $b$, and Car, regardless of treatment period, compared with the control. Given that all leaves of seedlings in the $1.0 \%$ treatment group with- ered off by $64 \mathrm{~d}$, no data were available for this time point. There were some exceptions in the treatments with a lower $\mathrm{NaCl}$ concentration. No significant difference was found between the $0.6 \%$ and $0.8 \%$ treatment groups at $64 \mathrm{~d}$ for all types of pigments, among $0.2 \%$ to $0.6 \%$ treatments at $8 \mathrm{~d}$ for $\mathrm{Chl} b$, and 


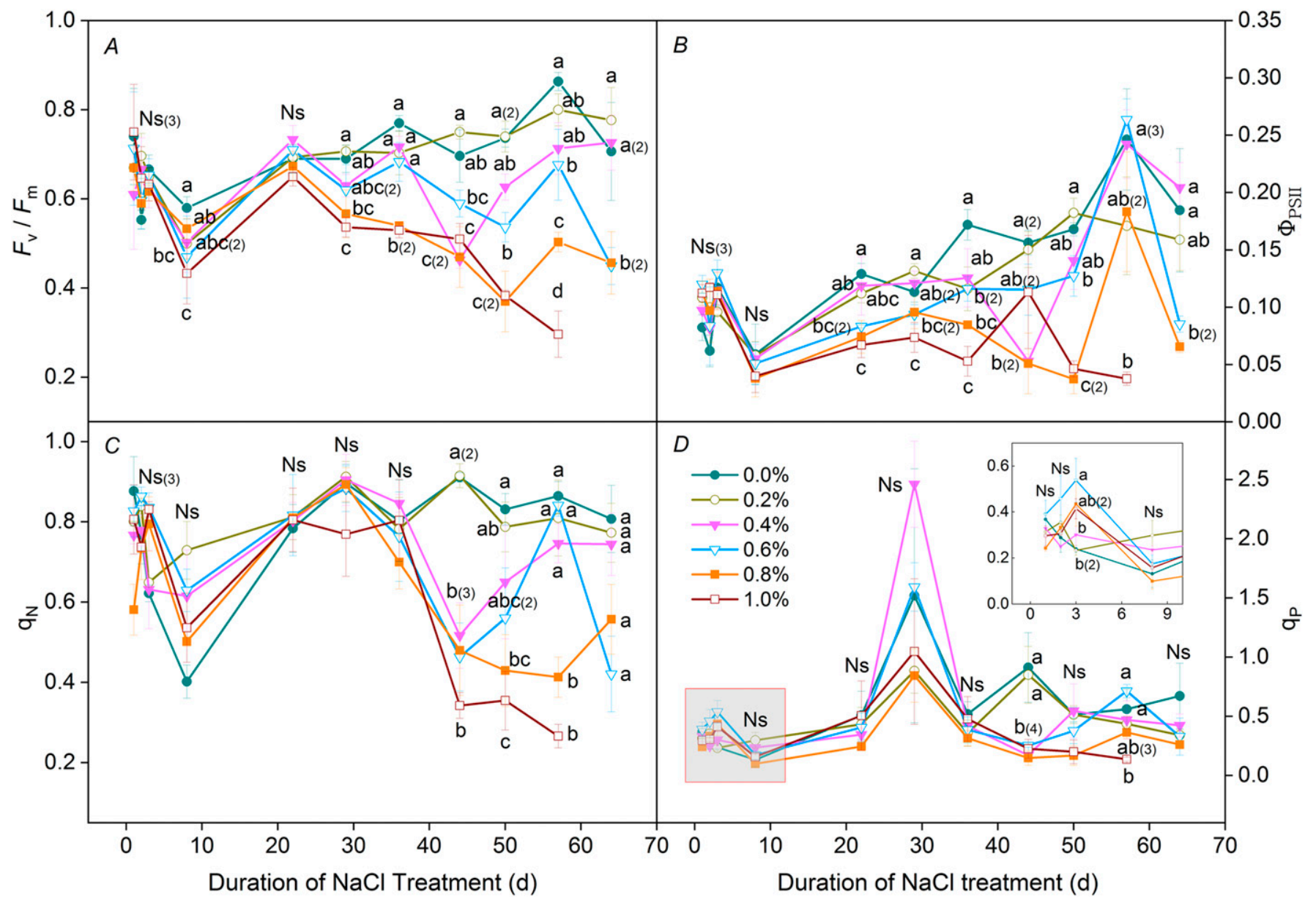

Fig. 3. Effects of $\mathrm{NaCl}$ on $(\mathbf{A})$ maximum quantum yield of photosystem II (PSII) photochemistry $\left(F_{\mathrm{v}} / F_{\mathrm{m}}\right),(\mathbf{B})$ actual quantum yield of PSII photochemistry $\left(\Phi_{\mathrm{PSII}}\right),(\mathbf{C})$ nonphotochemical quenching coefficient $\left(\mathrm{q}_{\mathrm{N}}\right)$, and $(\mathbf{D})$ photochemical quenching coefficient $\left(\mathrm{q}_{\mathrm{P}}\right)$ in leaves of 3-year-old ginkgo seedlings. Data are mean \pm sE, $\mathrm{n}=5$. Within the same time point, different letters indicate a significant difference by Duncan's multiple range test $(P<0.05)$.

among all less than $1.0 \%$-treated groups at $64 \mathrm{~d}$ for Car.

Changes in Chl fluorescence parameters under salinity stress. Fluorescence parameters (Fig. 3) can be used to monitor the growth, physiological response, and PSII changes in plants under stress. No significant differences in Chl fluorescence parameters were observed during the early stage of stress, and the $0.2 \%$ treatment did not have an effect in all observed periods, with one exception $\left(\Phi_{\mathrm{PSII}}\right.$ at $\left.36 \mathrm{~d}\right)$. For the $1.0 \%, 0.8 \%$, and $0.6 \% \mathrm{NaCl}$ treatments, a significant reduction in $F_{\mathrm{v}} / F_{\mathrm{m}}$ was observed at 29,36 , and $50 \mathrm{~d}$ of treatment, respectively (Fig. 3A), whereas $\Phi_{\text {PSII }}$ significantly decreased after 22, 36, and $64 \mathrm{~d}$ of treatment (Fig. 3B). For the $0.4 \%$ concentration, $F_{\mathrm{v}} / F_{\mathrm{m}}$ and $\Phi_{\text {PSII }}$ were unaffected, except at $44 \mathrm{~d}$, when a significant decrease occurred.

No significant differences in $\mathrm{q}_{\mathrm{N}}$ existed among different salinity groups before $36 \mathrm{~d}$ of treatment, whereas a strong decline in $\mathrm{q}_{\mathrm{N}}$ of seedlings exposed to $0.8 \%$ and $1.0 \% \mathrm{NaCl}$ was observed compared with controls after 44 to $57 \mathrm{~d}$ of treatment. In the $0.4 \%$ and $0.6 \%$ groups, a significant reduction was found at $44 \mathrm{~d}$. For $\mathrm{q}_{\mathrm{P}}$, significant differences were detected in salt-treated seedlings at 3 , 44, and $57 \mathrm{~d}$.

Cell damage induced by salt treatment. Changes in REC are commonly used as indicators of cell membrane permeability induced by cell damage. As shown in Fig. 4A, REC largely increased as $\mathrm{NaCl}$ concentration and treatment day increased. Although the $0.2 \%$ treatment did not have a significant effect at 8 and $36 \mathrm{~d}$, REC increased significantly at 15 and $64 \mathrm{~d}$ for $0.2 \%$ $\mathrm{NaCl}$. No significant difference was found between the $0.6 \%$ and $0.8 \%$ treatments, regardless of treatment day. The greatest REC value was found in the $36-\mathrm{d} 1.0 \%$ treatment group, which more than tripled the control value.

Effects on antioxidant systems under salinity stress. When common stress-related markers were examined (Fig. 4B-F), their activities or contents largely showed an increasing trend, with the exception of MDA, which decreased, compared with the $0 \%$ $\mathrm{NaCl}$ control (Fig. 4B). During the early stages of salt stress, no significant differences in GSH levels were observed. As salt treatment concentration and duration increased, GSH level increased significantly (Fig. 4C). Flavonoid content was significantly high in all $\mathrm{NaCl}$ treatments and time points (Fig. 4D). For CAT, none of the treatments had an effect at 8 and $64 \mathrm{~d}$ (Fig. 4E). SOD activity increased in all $\mathrm{NaCl}$ concentrations and time points, except for $0.2 \%$ at $8 \mathrm{~d}$ (Fig. 3F). POD increased in all $\mathrm{NaCl}$ concentrations and time points with two exceptions $-0.2 \% \mathrm{NaCl}$ at $\mathrm{n}$ $8 \mathrm{~d}$ and $0.8 \%$ at $15 \mathrm{~d}$, which were similar to the control (Fig. $4 \mathrm{G}$ ). At $15 \mathrm{~d}, 0.2 \%$ to $0.6 \%$ $\mathrm{NaCl}$ decreased the scavenging rate on DPPH free radicals, whereas greater concentrations did not have an effect (Fig. 4H). In comparison, $0.2 \%$ and $0.4 \% \mathrm{NaCl}$ decreased the scavenging rate on the hydroxyl radical in $64 \mathrm{~d}$, but $0.6 \%$ and $0.8 \% \mathrm{NaCl}$ showed results similar to the control (Fig. 4I).

Correlation and principle component analyses. $\mathrm{NaCl}$ treatment had a significant correlation relationship with all traits being studied in at least one of the time points (Fig. 5). In particular, $\mathrm{NaCl}$ had a positive correlation with REC and a negative correlation with $F_{\mathrm{v}} / F_{\mathrm{m}}$, Chl $(a+b)$, and Chl $a$ on all treatment days. At $64 \mathrm{~d}$, the correlation of $\mathrm{NaCl}$ with plant and soil water potentials, plant height, and ground diameter was significantly negative. $\mathrm{NaCl}$ generally exhibited a significantly positive correlation with 

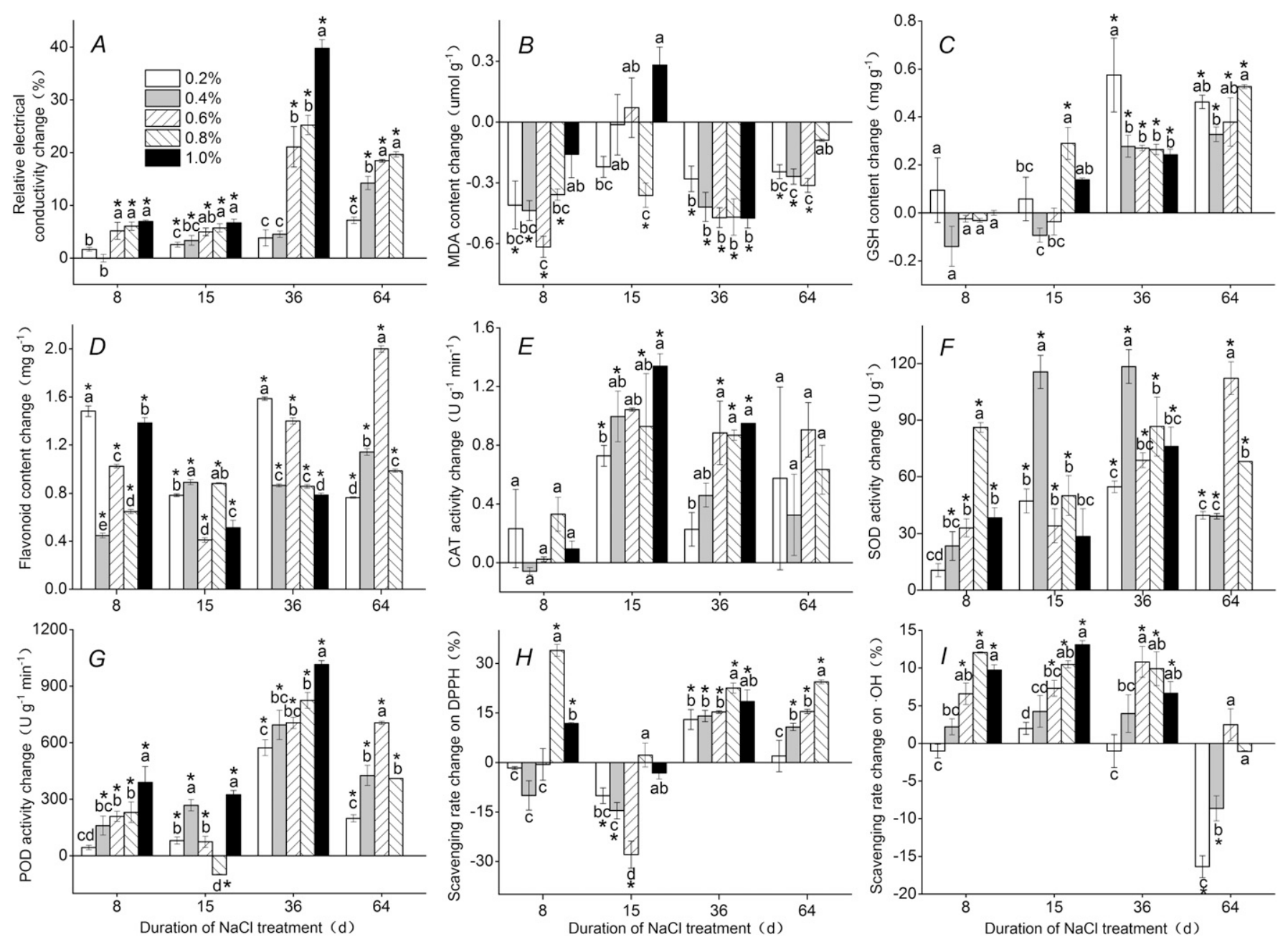

Fig. 4. Effects of $\mathrm{NaCl}$ on (A) relative electrical conductivity, (B) level of malondialdehyde (MDA), (C) reduced glutathione (GSH), and (D) flavonoid; (E) activity of catalase (CAT), (F) superoxide dismutase (SOD), and (G) peroxidase (POD); and (H) scavenging rate on diphenyl picrylhydrazyl (DPPH) and (I) hydroxyl radical $(\bullet \mathrm{OH})$ in 3-year-old ginkgo seedlings. Data represent changes compared with the control $(0 \% \mathrm{NaCl})$ and are mean $\pm \mathrm{SE}, \mathrm{n}=5$. Within the same time point, different letters represent significant difference among $0.2 \%$ to $1.0 \% \mathrm{NaCl}$ treatments; $*$ indicates significant difference from the control $(P<0.05)$.

stress-related markers and a negative correlation with $\mathrm{Chl}$ fluorescence indexes.

As expected, a positive relationship existed between soil and plant water potential. Plant height and stem ground diameter had a positive relationship with Chl, Car, $F_{\mathrm{v}} / F_{\mathrm{m}}$, and $\Phi_{\mathrm{PSI}}$, with the exception of plant height with Car. Enzymes and activities related to ROS scavenging mostly had a positive correlation among them and had a negative correlation with $\mathrm{Chl}$ fluorescence indices. Interestingly, a negative relationship was found between REC and MDA.

Principle component analysis identified five components that contributed to $90 \%$ of the response variations in $\mathrm{NaCl}$ treatment (Table 1). The major indices (absolute coefficient, >0.7) in each component were the scavenging rate of the hydroxyl radical, Chl $b$, Chl $(a+b), F_{\mathrm{v}} / F_{\mathrm{m}}$, and Car; plant water potential, GSH, and soil water potential; MDA, flavonoid, and POD; $\mathrm{q}_{\mathrm{N}}$ and $\mathrm{q}_{\mathrm{P}}$; and CAT (Table 2). Among these indices, the scavenging rate of the hydroxyl radical, Car, GSH, and MDA had a negative coefficient, whereas the rest had a positive coefficient.

\section{Discussion}

Ginkgo, also known as the maidenhair tree, is generally regarded as tolerant to environmental stresses. We reported previously that the height and ground diameter of 3-year-old ginkgo seedlings were not affected adversely until the $\mathrm{NaCl}$ concentration reached $0.6 \%$ and $0.8 \%$, respectively (Zhao et al., 2018). This condition is comparable to that for 6-month-old poplar cuttings (Populus euphratica), in which the $\geq 0.88 \% \mathrm{NaCl}$ treatment for 2 months reduced diameter and height growth (Neko et al., 2018). In contrast, the growth rate of silver maple (Acer saccharinum L.), a less-tolerant species, was affected by $0.3 \% \mathrm{NaCl}$ (Patykowski et al., 2018). When comparing salt tolerance among several 1-year-old tree species, Sun et al. (2009) reported that a $0.2 \% \mathrm{NaCl}$ treatment led to growth inhibition of stem height and diameter in Platanus occidentalis. For Gleditsia triacanthos, Quercus virginiana, Myrica cerifera, Fraxinus pennsylvanica, and Salix matsudana, the stem-diameter/growth-inhibiting $\mathrm{NaCl}$ concentration was $0.4 \%$. For stem height, $G$. triacanthos and $F$. pennsylvanica were affected negatively by $0.4 \% \mathrm{NaCl}$, whereas $Q$. virginiana and $M$. cerifera were affected negatively by $0.6 \% \mathrm{NaCl}$. In our previous study, SEM revealed a large number of salt crystal clusters in the stem parenchyma cells of salt-treated ginkgo seedlings (Zhao et al., 2018). Thus, compartmentation may be a mechanism used in ginkgo for salt tolerance.

Chl is an important component of pigment-protein complexes on the thylakoid membrane, which reflects plant photosynthetic capacity. This component plays an important role in capturing and transmitting light energy in photosynthesis and is one of the most important indicators of salt tolerance. In the current study, $\mathrm{Chl} a$ and $\mathrm{Chl} b$ contents decreased gradually as $\mathrm{NaCl}$ treatment concentration and duration increased, which agreed with the results seen in other species, such as apple (Jia et al., 2019) and 


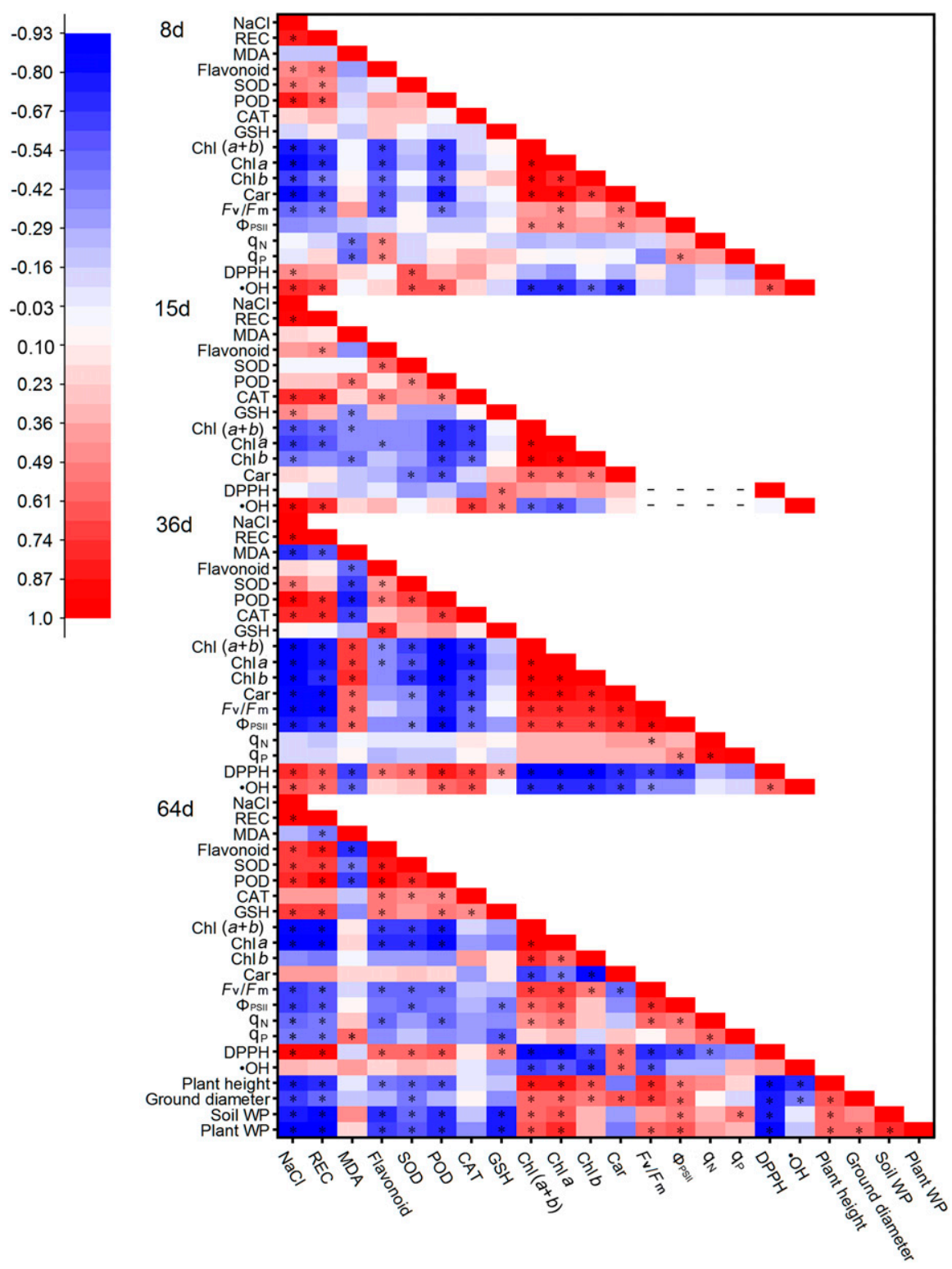

Fig. 5. Pearson correlation coefficients among studied traits in 3-year-old ginkgo seedlings. An asterisk indicates significant differences at $P<0.05$. REC, relative electrical conductivity; MDA, malondialdehyde; SOD, superoxide dismutase; POD, peroxidase; CAT, catalase; GSH, reduced glutathione; $\mathrm{Chl}$, chlorophyll; Car, carotenoids; $F_{\mathrm{v}} / F_{\mathrm{m}}$, maximum quantum yield of photosystem II (PSII) photochemistry; $\Phi_{\text {PSII }}$, actual quantum yield of PSII photochemistry; $\mathrm{q}_{\mathrm{N}}$, nonphotochemical quenching coefficient; qP, photochemical quenching coefficient; DPPH, diphenyl picrylhydrazyl; $\bullet \mathrm{OH}$, hydroxyl radical; WP, water potential.

Table 1. Results of principal component analysis of 19 indexes of 3-year-old ginkgo seedlings under $\mathrm{NaCl}$ stress for $64 \mathrm{~d}$.

\begin{tabular}{lccc}
\hline Principal component & Initial eigenvalue & Contribution rate (\%) & Cumulative contribution rate (\%) \\
\hline 1 & 5.179 & 27.260 & 27.260 \\
2 & 4.454 & 23.440 & 50.700 \\
3 & 3.836 & 20.190 & 70.890 \\
4 & 1.953 & 10.281 & 81.171 \\
5 & 1.680 & 8.844 & 90.015 \\
\hline
\end{tabular}

cucumber (Stepień and Kłobus, 2006). The decrease in Chl content may be attributed to increased degradation and inhibited synthesis of the pigment. The loss of Chl is usually accompanied by inactivation of photochemical reactions, especially those mediated by PSII in plants exposed to salt stress (Sharma and Hall, 1992). Enhanced less only in our $1.0 \% \mathrm{NaCl}$ groups compared with the control group, whereas Chl $a$ and Car contents were affected by lower concentrations, indicating that $\mathrm{Chl} b$ was more stable under salt stress. This finding is in contrast with the results of a previous study of the European searocket (Cakile maritima) (Megdiche et al., 2008). This inconsistency may be the result of the different degrees to which chloroplasts are affected by ionic toxicity during the early stages of salt stress. Different plants may also have different $\mathrm{Chl} b$ responses. During the later stage ( $64 \mathrm{~d}), \mathrm{Chl} b$ content increased in the $0.2 \% \mathrm{NaCl}$ treatment group, indicating that low $\mathrm{NaCl}$ concentrations can promote photosynthesis. This result is consistent with the findings from ginkgo suspension cells (Chen et al., 2014). Car can play a role in light protection by helping dissipate excess light energy in PSI and PSII by thermal and chemical reactions under stress (Lu et al., 2003). No significant differences in Car were observed between the treatments and control groups at $64 \mathrm{~d}$. This finding suggests that Car is relatively stable and exhibits some tolerance to salt stress, which may help in scavenging active oxygen and protecting the photosynthetic membrane.

We reported previously that $0.2 \% \mathrm{NaCl}$ enhanced the net photosynthesis rate $\left(\mathrm{P}_{\mathrm{n}}\right)$ during 1 to $35 \mathrm{~d}$ of treatment, but greater $\mathrm{NaCl}$ treatments reduced $\mathrm{P}_{\mathrm{n}}$ from day 1 (Zhao et al., 2018). Stomatal conductance was affected negatively by salt stress. However, water use efficiency was enhanced, at least under low salinity and short exposure. In the current study, the yield of Chl fluorescence emission was investigated. Chl fluorescence provides valuable information about the quantum efficiency of photochemistry and heat dissipation, and is commonly used as a criterion for photosystem efficiency. $F_{\mathrm{v}} / F_{\mathrm{m}}$ reflects the maximum light energy conversion efficiency of PSII after adaptation to darkness, indicating that photoinhibition reflects the efficiency of light energy conversion in the active center of PSII (Lichtenthaler and Burkart, 1999). $\Phi_{\text {PSII }}$ reflects the actual photochemical efficiency when the PSII reaction center is partly shut down under light. In the current study, Chl fluorescence parameters for different salt treatments were not significantly different from those of controls during the early stage of stress, indicating that PSII was unaffected. As salt treatment concentration and duration increased, $F_{\mathrm{v}} / F_{\mathrm{m}}$ and $\Phi_{\mathrm{PSII}}$ decreased gradually in the medium- and high-concentration treatment groups $(0.6 \%$ to $1.0 \%)$, and stability of the membrane system was seriously affected at $0.6 \% \mathrm{NaCl}$ and more, suggesting the aggravation of the PSII reaction center at greater stress levels (Lu and Zhang, 2000). It has been similarly reported that an $F_{\mathrm{v}} / F_{\mathrm{m}}$ value less than 0.6 indicates serious disturbances in PSII performance (Percival, 2005), and this corresponds with diminished photosynthesis (Kalaji et al., 2011; Percival and Sheriffs, 2002). Additional effects of salt 
Table 2. Component matrix of 3-year-old ginkgo seedlings under $\mathrm{NaCl}$ stress for $64 \mathrm{~d}$.

\begin{tabular}{|c|c|c|c|c|c|}
\hline Index & Component 1 & Component 2 & Component 3 & Component 4 & Component 5 \\
\hline$\cdot \mathrm{OH}$ radical scavenging rate & -0.934 & 0.167 & 0.026 & 0.092 & 0.059 \\
\hline Chl b & 0.806 & 0.080 & -0.221 & 0.005 & 0.511 \\
\hline Chl $(a+b)$ & 0.783 & 0.371 & -0.403 & 0.167 & 0.059 \\
\hline$F_{\mathrm{v}} / F_{\mathrm{m}}$ & 0.777 & 0.332 & -0.031 & 0.280 & -0.257 \\
\hline Car & -0.718 & -0.349 & -0.061 & 0.138 & -0.404 \\
\hline Chl $a$ & 0.676 & 0.449 & -0.432 & 0.216 & -0.143 \\
\hline Water potential of branch & 0.325 & 0.859 & -0.265 & 0.071 & -0.175 \\
\hline GSH & 0.169 & -0.858 & 0.221 & -0.240 & 0.196 \\
\hline Water potential of soil & 0.134 & 0.784 & -0.435 & 0.159 & 0.096 \\
\hline DPPH radical scavenging rate & -0.574 & -0.690 & 0.241 & -0.208 & -0.078 \\
\hline REC & -0.364 & -0.672 & 0.586 & -0.155 & 0.079 \\
\hline$\Phi_{\text {PSII }}$ & 0.457 & 0.543 & 0.011 & 0.401 & -0.265 \\
\hline MDA & -0.341 & 0.104 & -0.852 & 0.280 & 0.125 \\
\hline Flavonoid & -0.262 & -0.341 & 0.826 & -0.169 & 0.234 \\
\hline POD & -0.334 & -0.354 & 0.814 & -0.186 & 0.201 \\
\hline SOD & -0.387 & -0.314 & 0.666 & 0.039 & 0.347 \\
\hline $\mathrm{q}_{\mathrm{N}}$ & 0.331 & 0.139 & -0.189 & 0.834 & -0.160 \\
\hline $\mathrm{q}_{\mathrm{P}}$ & -0.285 & 0.356 & -0.310 & 0.773 & -0.007 \\
\hline CAT & 0.081 & -0.204 & 0.278 & -0.145 & 0.864 \\
\hline
\end{tabular}

$\cdot \mathrm{OH}=$ hydroxyl radical; $\mathrm{Chl}=$ chlorophyll; $F_{\mathrm{v}} / F_{\mathrm{m}}=$ maximum quantum yield of photosystem II (PSII) photochemistry; $\mathrm{Car}=$ carotenoids; $\mathrm{GSH}=$ reduced glutathione; $\mathrm{DPPH}=$ diphenyl picrylhydrazyl; $\mathrm{REC}=$ relative electrical conductivity; $\mathrm{MDA}=$ malondialdehyde; $\mathrm{POD}=$ peroxidase $; \mathrm{SOD}=$ superoxide dismutase; $\mathrm{q}_{\mathrm{N}}=$ nonphotochemical quenching coefficient; $\mathrm{q}_{\mathrm{P}}=$ photochemical quenching coefficient; $\mathrm{CAT}=$ catalase

may be evoked by yearly salt accumulation in perennial trees (Zhao et al., 2018) and may lead to increasing leaf injuries (Swoczyna et al., 2009). In additiona, light energy conversion efficiency and use were less, and photosynthesis was inhibited. These results reflect what was observed in ginkgo suspension cells (Chen et al., 2014), and species such as Elaeagnus oxycarpa Linn. (Maimaiti et al., 2014) and Calendula officinalis (Baniasadi et al., 2018), upon exposure to $\mathrm{NaCl}$. In ginkgo seedlings treated with low concentrations of $\mathrm{NaCl}$, a significant decrease in $\Phi_{\text {PSII }}$ was detected only after 36 and $44 \mathrm{~d}$ of treatment.

Chl fluorescence quenching is an approach by which energy dissipates in chloroplasts. The $\mathrm{q}_{\mathrm{P}}$ value reflects the aperture opening degree, PSII reaction center activity, and conversion efficiency of the captured light quantum into chemical energy. $\mathrm{q}_{\mathrm{N}}$ estimates the rate constant for heat loss from PSII. Before $36 \mathrm{~d}$, salt treatment did not affect $\mathrm{q}_{\mathrm{N}}$ and $\mathrm{q}_{\mathrm{P}}$, regardless of $\mathrm{NaCl}$ concentration, reflecting the capacity of young ginkgo seedlings to dissipate heat under salt stress. Decreased $\mathrm{q}_{\mathrm{N}}$ and $\mathrm{q}_{\mathrm{P}}$ were found only in high salt concentrations after $36 \mathrm{~d}$, indicating the exacerbation of damage to the plants. Although these results were different from the ones from ginkgo suspension cultures (Chen et al., 2014) and Cakile maritima (Megdiche et al., 2008), they are consistent in part with the reports for Medicago arborea (Boughalleb et al., 2009).

The membrane system is the barrier of material and information exchange between plant cells and their surroundings. Its integrity and stability are important for maintaining normal physiological activities in plants. Excessive accumulation of $\mathrm{Na}^{+}$can shift the original balance of free radicals in cells, thus causing membrane lipid peroxidation, which reduces membrane fluidity, increases perme- ability and electrolyte leakage, and affects metabolic processes (Ahmad et al., 2014). In the current study, as treatment duration progressed, membrane permeability (REC value) first increased and then decreased, indicating that seedling cell permeability had been noticeably damaged. This result is consistent with reports for coastal C. maritima seedlings (Amor et al., 2010). MDA results from the lipid peroxidation of polyunsaturated fatty acids and is an indicator of free radical production and consequent tissue damage. MDA accumulation generally increases along with REC (Tounekti et al., 2011). An opposite correlation was observed in the current study. This condition may be a salinity tolerance mechanism of ginkgo seedlings, similar to tolerant ramie (Boehmeria nivea) plants. Huang et al. (2015) reported that the trends of MDA content in salttolerant and salt-sensitive ramie cultivars were completely disparate when exposed to salinity. Although REC increased in both cultivars, MDA increased in the sensitive cultivar but decreased in the tolerant one.

Plants have enzymatic and nonenzymatic antioxidant systems. SOD, POD, and CAT are important protective enzymes in the plant enzymatic defense system. These enzymes relieve damage caused by membrane lipid peroxides (Wu et al., 2014). The collaboration of SOD, POD, and CAT effectively prevents lipid peroxidation; reduces membrane damage caused by ROS; and improves salt tolerance. During the early stages of salt stress in the current study, SOD, POD, and CAT activities were all enhanced, consistent with observations for Thellungiella halophila (Radyukina et al., 2007). Moreover, a significant positive correlation was observed between membrane permeability and hydroxyl radical scavenging activity during the early stages of stress ( 8 and $15 \mathrm{~d}$ ). Membrane permeability correlated significantly with
POD and SOD at $8 \mathrm{~d}$, and with CAT at $15 \mathrm{~d}$. These results indicate different response times among SOD, POD, and CAT. Rasool et al. (2013) proposed that SOD produces superoxide anion radicals to form $\mathrm{H}_{2} \mathrm{O}_{2}$ and peroxide during the early stages of salt stress and then scavenges excessive $\mathrm{H}_{2} \mathrm{O}_{2}$ together with POD and CAT. This process may be the main reason for the slow increase in membrane permeability that we observed during the early stages of salt stress. As treatment concentration and duration increased, SOD, POD, and CAT activities first increased and then decreased, indicating that their synthesis was suppressed, which is consistent with a study of Lolium perenne ( $\mathrm{Hu}$ et al., 2012).

GSH is an effective nonenzymatic antioxidant that protects proteins with sulfhydryl groups, participates in transmembrane transport of amino acids, and effectively improves plant stress tolerance. During salt treatment in the current study, no significant changes in GSH levels were observed after $8 \mathrm{~d}$, but a significant increase was detected after $15 \mathrm{~d}$, indicating that the response of GSH production to salt stress occurred at a later period. In recent decades, exogenous GSH has been applied successfully to alleviate stress damage in Malus robusta (Bai et al., 2009). Abundant flavonoids are present in ginkgo leaves, which protect cells and chromosomes from ROS damage (Agati et al., 2012). In the current study, the flavonoid content in ginkgo leaves increased significantly after salt treatment, indicating that flavonoid production and accumulation had a positive response to salt stress; this finding is analogous to those found previously in ginkgo cells (Chen et al., 2014).

In conclusion, severe salt stress decreases pigment content and activity of photosynthetic electron transport $\left(\Phi_{\mathrm{PSII}}, \mathrm{q}_{\mathrm{P}}\right)$, inhibits conversion $\left(F_{\mathrm{v}} / F_{\mathrm{m}}\right)$ of light energy, and destroys cell membrane structure (REC) in ginkgo seedlings. However, Chl fluorescence is unaffected under low salt stress, and growth is only affected under severe stress. Therefore, ginkgo seedlings are tolerant only to low salt stress. The current study suggests that active enzymatic and nonenzymatic antioxidant systems work synergistically to reduce lipid oxidation under $\mathrm{NaCl}$ stress. The reduced accumulation of MDA under salt stress warrants further investigation because of its possible association with tolerance. Last, correlation and principal component analyses indicated that water potential, $\mathrm{Chl}$ fluorescence parameters, activities of POD and SOD, contents of CAT and flavonoids, and hydroxyl and DPPH free radical scavenging capability are sensitive to salt stress and can be used for in vitro or rapid and nondestructive monitoring of the responses of ginkgo seedlings to salinity stress.

\section{Literature Cited}

Aebi, H. 1984. Catalase in vitro. Methods Enzymol. 105:121-126. 
Agati, G., E. Azzarello, S. Pollastri, and M. Tattini. 2012. Flavonoids as antioxidants in plants: Location and functional significance. Plant Sci. 196:67-76.

Ahmad, P., M. Ozturk, S. Sharma, and S. Gucel. 2014. Effect of sodium carbonate-induced salinity-alkalinity on some key osmoprotectants, protein profile, antioxidant enzymes, and lipid peroxidation in two mulberry (Morus alba L.) cultivars. J. Plant Interact. 9:460-467.

Amor, N.B., W. Megdiche, A. Jiménez, F. Sevilla, and C. Abdelly. 2010. The effect of calcium on the antioxidant systems in the halophyte Cakile maritima under salt stress. Acta Physiol. Plant. 32:453-461.

Apel, K. and H. Hirt. 2004. Reactive oxygen species: Metabolism, oxidative stress, and signal transduction. Annu. Rev. Plant Biol. 55:373-399.

Arnon, D.I. 1949. Copper enzymes in isolated chloroplasts: Polyphenoloxidase in Beta vulgaris. Plant Physiol. 24:1-15.

Bai, T., C. Li, F. Ma, H. Shu, and M. Han. 2009. Exogenous salicylic acid alleviates growth inhibition and oxidative stress induced by hypoxia stress in Malus robusta Rehd. J. Plant Growth Regul. 28:358-366.

Baniasadi, F., V.R. Saffari, and A.A.M. Moud. 2018. Physiological and growth responses of Calendula officinalis L. plants to the interaction effects of polyamines and salt stress. Scientia Hort. 234:312-317.

Bidalia, A., M. Hanief, and K.S. Rao. 2017 Tolerance of Mitragyna parvifolia (Roxb.) Korth. seedlings to $\mathrm{NaCl}$ salinity. Photosynthetica 55:231-239.

Boughalleb, F., M. Denden, and B.B. Tiba. 2009 Photosystem II: Photochemistry and physiological parameters of three fodder shrubs, Nitraria retusa, Atriplex halimus and Medicago arborea under salt stress. Acta Physiol. Plant. 31:463-476.

Breckle, S.W. 1995. How do halophytes overcome salinity? p. 199-213. In: M.A. Khan and I.A. Ungar (eds.). Biology of salt tolerant plants. Book Graffers, Chelsea, MI.

Chen, Y., F. Lin, H. Yang, L. Yue, F. Hu, J. Wang, Y. Luo, and F. Cao. 2014. Effect of varying $\mathrm{NaCl}$ doses on flavonoid production in suspension cells of Ginkgo biloba: Relationship to chlorophyll fluorescence, ion homeostasis, antioxidant system and ultrastructure. Acta Physiol. Plant. 36:3173-3187.

DeFeudis, F.V., V. Papadopoulos, and K. Drieu. 2003. Ginkgo biloba extracts and cancer: A research area in its infancy. Fundam. Clin. Pharmacol. 17:405-417.

Dmuchowski, W., P. Brągoszewska, D. Gozdowski, A.B. Baczewska-Dabrowska, T. Chojnacki, A Jozwiak, E. Swiezewska, B. Gworek, and I. Suwara. 2019. Strategy of Ginkgo biloba L. in the mitigation of salt stress in the urban environment. Urban For. Urban Greening 38:223-231.

Genty, B., J.-M. Briantais, and N.R. Baker. 1989. The relationship between the quantum yield of photosynthetic electron transport and quenching of chlorophyll fluorescence. Biochim. Biophys. Acta 990:87-92.

Gong, W., Z. Zeng, Y.Y. Chen, C. Chen, Y.X. Qiu, and C.X. Fu. 2008. Glacial refugia of Ginkgo biloba and human impact on its genetic diversity: Evidence from chloroplast DNA. J. Integr. Plant Biol. 50:368-374.

Greenway, H. and R. Munns. 1980. Mechanisms of salt tolerance in nonhalophytes. Annu. Rev. Plant Physiol. 31:149-190.

Grieve, C.M., L.E. Francois, and E.V. Maas. 1994. Salinity affects the timing of phasic develop- ment in spring wheat. Crop Sci. 34:15441549.

Guan, R., Y. Zhao, H. Zhang, G. Fan, X. Liu, W. Zhou, C. Shi, J. Wang, W. Liu, X. Liang, Y. Fu, K. Ma, L. Zhao, F. Zhang, Z. Lu, S.M.-Y. Lee, X. Xu, J. Wang, H. Yang, C. Fu, S. Ge, and W. Chen. 2016. Draft genome of the living fossil Ginkgo biloba. Gigascience 5:1-13.

Gupta, B. and B. Huang. 2014. Mechanism of salinity tolerance in Plants: Physiological, biochemical, and molecular characterization. Intl. J. Genomics 2014:1-18, doi: 10.1155/2014/701596.

Guri, A. 1983. Variation in glutathione and ascorbic acid content among selected cultivars of Phaseolus vulgaris prior to and after exposure to ozone. Can. J. Plant Sci. 63:733-737.

Handa, M., Y. Iizuka, and N. Fujiwara. 1997 Ginkgo landscapes, p. 259-283. In: T. Hori., R.W. Ridge, W. Tulecke, P. Del Tredici, J Trémouillaux-Guiller, and H. Tobe (eds.) Ginkgo biloba, a global treasure: From biology to medicine. Springer-Verlag, Tokyo, Japan.

Havaux, M., R.J. Strasser, and H. Greppin. 1991. A theoretical and experimental analysis of the $\mathrm{q}_{\mathrm{P}}$ and $\mathrm{q}_{\mathrm{N}}$ coefficients of chlorophyll fluorescence quenching and their relation to photochemical and nonphotochemical events. Photosynth. Res. 27:41-55.

Heath, R.L. and L. Packer. 1965. Effect of light on lipid peroxidation in chloroplasts. Biochem. Biophys. Res. Commun. 19:716-720.

Hsu, C.F., L. Zhang, H. Peng, J. Travas-Sejdic, and P.A. Kilmartin. 2008. Scavenging of DPPH free radicals by polypyrrole powders of varying levels of overoxidation and/or reduction. Synth. Met. 158:946-952.

Hu, L., H. Li, H. Pang, and J. Fu. 2012. Responses of antioxidant gene, protein and enzymes to salinity stress in two genotypes of perennial ryegrass (Lolium perenne) differing in salt tolerance. J. Plant Physiol. 169:146-156.

Huang, C.J., G. Wei, Y.C. Jie, J.J. Xu, S.Y. Zhao, L.C. Wang, and S.A. Anjum. 2015. Responses of gas exchange, chlorophyll synthesis and ROS-scavenging systems to salinity stress in two ramie (Boehmeria nivea L.) cultivars Photosynthetica 53:455-463.

Jia, X.M., H. Wang, S. Svetla, Y.F. Zhu, Y. Hu, L. Cheng, T. Zhao, and Y.X. Wang. 2019. Comparative physiological responses and adaptive strategies of apple Malus halliana to salt, alkali and saline-alkali stress. Scientia Hort. 245:154 162.

Jia, Z., M. Tang, and J. Wu. 1999. The determination of flavonoid contents in mulberry and their scavenging effects on superoxide radicals. Food Chem. 64:555-559.

Kalaji, H.M., Govindjee, K. Bosa, J. Kościelniak, and K. Żuk-Golaszewska. 2011. Effects of salt stress on photosystem II efficiency and $\mathrm{CO}_{2}$ assimilation of two Syrian barley landraces. Environ. Exp. Bot. 73:64-72.

Liang, Y. and W.Q. Sun. 2002. Rate of dehydration and cumulative desiccation stress interacted to modulate desiccation tolerance of recalcitrant cocoa and ginkgo embryonic tissues. Plant Physiol. 128:1323-1331.

Lichtenthaler, H.K. 1987. Chlorophylls and carotenoids: Pigments of photosynthetic biomembranes. Methods Enzymol. 148:350-382.

Lichtenthaler, H.K. and S. Burkart. 1999. Photosynthesis and high light stress. Bulg. J. Plant Physiol. 25:3-16.

Lu, C., G. Jiang, B. Wang, and T. Kuang. 2003. Photosystem II photochemistry and photosynthetic pigment composition in salt-adapted halophyte Artimisia anethifolia grown under outdoor conditions. J. Plant Physiol. 160:403408.

Lu, C. and J. Zhang. 2000. Role of light in the response of PSII photochemistry to salt stress in the cyanobacterium Spirulina platensis. J. Expt. Bot. 51:911-917.

Maimaiti, A., Q. Yunus, F. Iwanaga, N. Mori, K. Tanaka, and N. Yamanaka. 2014. Effects of salinity on growth, photosynthesis, inorganic and organic osmolyte accumulation in Elaeagnus oxycarpa seedlings. Acta Physiol. Plant. 36:881-892.

Mathew, S. and T.E. Abraham. 2006. Studies on the antioxidant activities of cinnamon (Cinnamomum verum) bark extracts, through various in vitro models. Food Chem. 94:520-528.

Matoh, T. and S. Murata. 1990. Sodium stimulates growth of Panicum coloratum through enhanced photosynthesis. Plant Physiol. 92:11691173.

Megdiche, W., K. Hessini, F. Gharbi, C.A. Jaleel, R. Ksouri, and C. Abdelly. 2008. Photosynthesis and photosystem 2 efficiency of two saltadapted halophytic seashore Cakile maritima ecotypes. Photosynthetica 46:410-419.

Munns, R. and M. Tester. 2008. Mechanisms of salinity tolerance. Annu. Rev. Plant Biol. 59:651-681.

Neko, H.T., A. Shirvany, M.H. Assareh, M.R. Naghavi, M. Pessarakli, and A. Pourmeidani. 2018. Effects of $\mathrm{NaCl}$ on growth, yield and ion concentration of various Populus euphratica Oliv. ecotypes in Iran. Desert 23:189-198.

Pardo, J.M., M.P. Reddy, S. Yang, A. Maggio, G.-H. Huh, T. Matsumoto, M.A. Coca, M. Paino-D’Urzo, H. Koiwa, D.-J. Yun, A.A. Watad, R.A. Bressan, and P.M. Hasegawa. 1998. Stress signaling through $\mathrm{Ca}^{2+} /$ calmodulin-dependent protein phosphatase calcineurin mediates salt adaptation in plants. Proc. Natl. Acad. Sci. USA 95:9681-9686.

Patykowski, J., J. Kołodziejek, and M. Wala. 2018. Biochemical and growth responses of silver maple (Acer saccharinum L.) to sodium chloride and calcium chloride. PeerJ 6:e5958.

Percival, G.C. 2005. The use of chlorophyll fluorescence to identify chemical and environmental stress in leaf tissue of three oak (Quercus) species. J. Arboric. 31:215-227.

Percival, G.C. and C.N. Sheriffs. 2002. Identification of drought-tolerant woody perennials using chlorophyll fluorescence. J. Arboric. 28:215-223

Polle, A., T. Otter, and F. Seifert. 1994. Apoplastic peroxidases and lignification in needles of Norway spruce (Picea abies L.). Plant Physiol. 106:53-60.

Radyukina, N.L., A.V. Kartashov, Y.V. Ivanov, N.I. Shevyakova, and V.V. Kuznetsov. 2007. Functioning of defense systems in halophytes and glycophytes under progressing salinity. Russ. J. Plant Physiol. 54:806-815.

Rainer, S., K. Roger, M. Georgios, M. Raphae, M. Heiko, H. Robert, and I. Ralf. 2018. Ginkgo biloba extract EGb $761^{\circledR}$ alleviates neurosensory symptoms in patients with dementia: A meta-analysis of treatment effects on tinnitus and dizziness in randomized, placebocontrolled trials. Clin. Interv. Aging 13:11211127.

Rasool, S., A. Ahmad, T.O. Siddiqi, and P. Ahmad. 2013. Changes in growth, lipid peroxidation and some key antioxidant enzymes in chickpea genotypes under salt stress. Acta Physiol. Plant. 35:1039-1050.

Sæbø, A., Ž. Borzan, C. Ducatillion, A. Hatzistathis, T. Lagerström, J. Supuka, J.L. García-Valdecantos, F. Rego, and J.V. Slycken. 2005. The selection 
of plant materials for street trees, park trees and urban woodland, p. 257-280. In: C.C. Konijnendijk, K. Nilsson, T.B. Randrup, and J. Schipperijn (eds.). Urban forests and trees. Springer, Berlin, Germany.

Seemann, J.R. and C. Critchley. 1985. Effects of salt stress on the growth, ion content, stomatal behaviour and photosynthetic capacity of a salt-sensitive species, Phaseolus vulgaris L. Planta 164:151-162.

Sharma, P.K. and D.O. Hall. 1992. Changes in carotenoid composition and photosynthesis in sorghum under high light and salt stresses. J. Plant Physiol. 140:661-666.

Silva, E.N., R.V. Ribeiro, S.L. Ferreira-Silva, R.A. Viégas, and J.A.G. Silveira. 2010. Comparative effects of salinity and water stress on photosynthesis, water relations and growth of Jatropha curcas plants. J. Arid Environ. 74:1130-1137.

Stępień, P. and G. Kłobus. 2006. Water relations and photosynthesis in Cucumis sativus L. leaves under salt stress. Biol. Plant. 50:610616.
Stewart, R.R.C. and J.D. Bewley. 1980. Lipid peroxidation associated with accelerated aging of soybean axes. Plant Physiol. 65:245-248.

Sun, C.C., H.Y. Zhao, and C.X. Zheng. 2017. Effects of $\mathrm{NaCl}$ stress on osmolyte and proline metabolism in Ginkgo biloba seedling. Plant Physiol. J. 53:470-476 (in Chinese with English abstract).

Sun, H.J., S.F. Wang, and Y.T. Chen. 2009. Effects of salt stress on growth and physiological index of 6 tree species. For. Res. 22:315-324 (in Chinese with English abstract).

Sun, J., L. Li, M. Liu, M. Wang, M. Ding, S. Deng, C. Lu, X. Zhou, X. Shen, X. Zheng, and S. Chen. 2010. Hydrogen peroxide and nitric oxide mediate $\mathrm{K}^{+} / \mathrm{Na}^{+}$homeostasis and antioxidant defense in $\mathrm{NaCl}$-stressed callus cells of two contrasting poplars. Plant Cell Tissue Org. 103:205-215.

Swoczyna, T., J. Borowski, and A. Zambrzycka. 2009. Phenological reactions of young streetside trees of Ginkgo biloba L. in Warsaw. Ann. Warsaw Univ. Life Sci. - SGGW, Hort Landsc. Architect. 30:161-171.

Swoczyna, T., H.M. Kalaji, S. Pietkiewicz, and J. Borowski. 2015. Ability of various tree species to acclimation in urban environments probed with the JIP-test. Urban For. Urban Greening 14:544-553.

Tounekti, T., A.M. Vadel, M. Oñate, H. Khemira, and S. Munné-Bosch. 2011. Salt-induced oxidative stress in rosemary plants: Damage or protection? Environ. Exp. Bot. 71:298-305.

Tredici, P.D. 2008. Wake up and smell the ginkgos. Arnoldia 66:11-21.

van Beek, T.A. and P. Montoro. 2009. Chemical analysis and quality control of Ginkgo biloba leaves, extracts, and phytopharmaceuticals. J. Chromatogr. 1216:2002-2032.

Wu, X., J. He, J. Chen, S. Yang, and D. Zha. 2014. Alleviation of exogenous 6-benzyladenine on two genotypes of eggplant (Solanum melongena Mill.) growth under salt stress. Protoplasma 251:169-176.

Zhao, H.Y., N. Wei, C.C. Sun, Y.L. Bai, and C.X. Zheng. 2018. Effects of salt stress on anatomic structure of tissue and photosynthesis in Ginkgo biloba seedlings. J. Beijing For. Univ. 40:28-41 (in Chinese with English abstract).

Zhu, J.K. 2002. Salt and drought stress signal transduction in plants. Annu. Rev. Plant Biol. $53: 247-273$. 